\title{
An Improved Differential Evolution Scheme for the Solution of Large-Scale Unit Commitment Problems
}

\author{
Chen-Sung CHANG \\ Department of Information Management, Nan-Kai Institute of Technology \\ No. 568, Chung Cheng Rd., Tsaotun, Nantou County, 542, Taiwan, R.O.C. \\ e-mail: cschang@nkut.edu.tw
}

Received: July 2008; revised: September 2009

\begin{abstract}
This paper presents an improved differential evolution (IDE) method for the solution of large-scale unit commitment (UC) problems. The objective of the proposed scheme is to determine the generation schedule which minimizes the total operating cost over a given time horizon subject to a variety of constraints. Through its use of enhanced acceleration and migration processes, the IDE method limits the population size required in the search procedure and is therefore an ideal candidate for the solution of large-scale combinatorial optimization problems. The effectiveness of the proposed approach is verified by performing a series of simulations based upon the practical Tai-Power System (TPS) and various other power systems presented in the literature. In general, the results show that the IDE scheme outperforms existing deterministic and stochastic optimization methods both in terms of the quality of the solutions obtained and the computational cost. Furthermore, it is found that the magnitude of the cost savings achieved by the IDE scheme compared to that obtained by the other optimization techniques increases as the number of generating units within the power system increases. Therefore, the proposed scheme represents a particularly effective technique for the solution of large-scale UC problems.
\end{abstract}

Keywords: unit commitment, differential evolution, improved differential evolution.

\section{Introduction}

As the start-up and operating costs of power stations continue to soar, energy planners are placing an increasing emphasis upon the need to optimize the operating costs of existing plants. Essentially, this requires power provider enterprises (PPEs) to limit their fuel costs by deliberately restricting the time for which each generating unit within the power system is on-line. However, while seeking to minimize production costs, PPEs must nevertheless ensure that the power system is capable of satisfying the time-varying energy demands imposed upon it at all times. In practice, therefore, PPEs must achieve a satisfactory compromise between production costs, which are directly related to the number of generating units on-line at any time, and the risk of unplanned power outages. The resulting unit commitment (UC) problem, in which the aim is to identify suitable on/off states of each generating unit at each time index over the specified time horizon 
such that the overall operating cost is minimized subject to certain constraints, is a complex optimization problem (Wood and Wollenberg, 1996). The optimal solution of the UC problem can only be obtained by performing a complete enumeration of all the feasible combinations of generating units within the network. In practice, this is a massive task since modern power systems typically comprise many different generating units of different types. As a result, the UC problem is most commonly formulated as a nonlinear, large-scale, mixed-integer combinational optimization problem.

Several solution techniques have been applied to solve the UC problem. These include deterministic, meta-heuristic, and hybrid approaches. Deterministic approaches include priority list (Sheble, 1990), mixed-integer programming (MIP; Mohan et al., 1992), dynamic programming (DP; Padhy, 2000), branch-and-bound (BB; Chen and Wang, 1993) and Lagrangian relaxation (LR; Ngundam et al., 2002). Although these methods are simple and fast, they suffer from numerical convergence and solution quality problems. They are hard to solve the real-sized problem because of computational efficient and/or solution accuracy. Recently, meta-heuristic approaches became popular in the application to overcome shortcomings of traditional optimization techniques (Misevičius and Rubliauskas, 2009). Techniques such as simulated annealing (SA; Zhuang and Galiana, 1990), genetic algorithms (GA; Kazarlis et al., 1996; Padhy, 2000), evolutionary programming (EP; Yang et al., 1996), Tabu search (TS; Mantawy et al., 1998), ant colony optimization (Sisworahardjo and El-Kaib, 2002) and particle swarm optimization (Ting et al., 2003) have been widely applied to solve the UC problem. These methods can accommodate more complicated constraints and are claimed to produce solutions of improved quality. Of the two optimization approaches presented above, the latter group appears to have the greatest potential for the solution of UC problems. The GA, EP, TS and swarm intelligence (SI) optimization algorithms are based on natural biological mechanisms (Dzemyda and Sakalauskas, 2009), whereas SA is derived from the principles of material science. However, regardless of their respective origins, these methods all provide a suitable means of solving combinatorial-type problems in a variety of decision-making arenas. Furthermore, these methods are subject to constant review and improvement with the aim of further enhancing their performance and applicability.

The differential evolution (DE) scheme developed by Stron and Price (1996, 1997, 1999) has emerged as one of the most powerful evolution algorithms (EAs). DE is a simple method based on stochastic search routines, in which the optimization function parameters are encoded as floating-point variables. However, although DE provides a convenient means of solving real-valued optimization problems, it has a tendency to converge prematurely to a local, sub-optimal solution. While this problem can be overcome to a certain extent by increasing the size of the searched population, this inevitably increases the computational time and expense. To resolve this problem, Chiou and Wang (1998) proposed a hybrid version of DE (designated as HDE), in which two additional operations, namely acceleration and migration, were introduced to improve both the speed and the thoroughness with which the solution space was searched. It was shown that these operations increased the likelihood of the scheme finding a global optimal solution. However, it was also found that the fitness characteristics of the best solutions in each 
generation did not converge smoothly from one generation to the next. Accordingly, Lin et al. (1999) proposed an enhanced acceleration operation designed specifically to improve the fitness evolution of the best candidates during the iterative solution of mixedinteger nonlinear optimization problems. The DE family of optimization schemes has been successfully applied to the solution of many real-world problems and has a proven ability to determine global optimal solutions. However, the UC problem considered in the present study includes both continuous and discrete variables and has the form of a joint combinatorial optimization and nonlinear optimization problem. Accordingly, an improved differential evolution (IDE) method is proposed to solve the problem in a rapid and efficient manner.

The remainder of this paper is organized as follows. Section 2 reviews the general UC problem and develops its mathematical formulation. Section 3 introduces the IDE scheme developed in this study to solve the UC problem. Section 4 verifies the performance of the proposed scheme by performing a series of numerical simulations based upon a variety of power systems of different scales and benchmarking the results against those obtained from conventional deterministic and stochastic optimization schemes. Finally, Section 5 provides some brief concluding remarks.

\section{Problem Description and Formulation}

The principal objective of the unit commitment (UC) of power systems is to schedule the generation units in order to serve the load demand at the minimum operating cost while meeting all system constraints (Wood and Wollenberg, 1996). Generation scheduling involves the determination of the start up-time and shut down-time points and the generation levels for each unit over a given scheduling period. The schedule is subject to a number of system and unit constraints. And some major constraints that must be taken into account include: (1) The total power output must meet the load demand plus system losses. (2) There must be enough spinning reserve to cover any shortfall in generation. (3) The generation of each unit must be within its minimum and maximum allowable power output range. (4) The minimum up- and down-times of thermal generation units must be considered. (5) Ramp rates limits for thermal generation units must not be violated.

In this study, the objective of the UC problem is to establish the generating unit schedule which minimizes the total operating cost over a specified time horizon subject to various constraints. In a power system, the operating cost consists primarily of the fuel costs incurred by the committed units (thermal or nuclear) and can be expressed in the following quadratic form:

$$
F C_{i}\left(P_{i h}\right)=a_{i} P_{i h}^{2}+b_{i} P_{i h}+c_{i},
$$

where $a_{i}, b_{i}, c_{i}$ cost function coefficients of unit $i\left(\$ / \mathrm{MW}^{2} \mathrm{~h}, \$ / \mathrm{MWh}, \$ / \mathrm{h}\right) ; F C_{i}\left(P_{i h}\right)$ production cost of unit $i$ at time $h(\$ / \mathrm{h}) ; P_{i h}$ output power from unit $i$ at time $h(\mathrm{MW})$. 


\subsection{Objective Function}

As stated above, the objective of the UC problem is to minimize the total production cost over the scheduling horizon. Therefore, the objective function can be expressed as the sum of the fuel costs and the start-up costs of the individual generating units in the power system, i.e.,

$$
\Phi(X, P)=\sum_{i=1}^{N} \sum_{h=1}^{H}\left[F C_{i}\left(P_{i h}\right)+S T C_{i}\left(1-X_{i(h-1)}\right)\right] * X_{i h},
$$

where $\Phi(\cdot)$ function of total production costs; $N$ number of generating units; $H$ number of hours; $P_{i h}$ generation output of unit $i$ at time $h ; X_{i h}$ ON/OFF status of unit $i$ at time $h$; where $X_{i h}=1(0)$ when unit is ON (OFF); $P$ generation matrix with elements $P_{i h}$, $i=1, \ldots, N ; h=1, \ldots, H ; X$ schedule matrix with elements $X_{i h}, i=1, \ldots, N$; $h=1, \ldots, H ; S T C_{i}$ start-up cost of unit $i$.

\subsection{Constraints}

Depending on the nature of the power system under review, the UC optimization problem is subject to various constraints, the main being those relating to the load balance and the spinning reserve, respectively, and the remainder relating to thermal constraints, fuel constraints, security constraints, and so forth (Wood and Wollenberg, 1996).

1) Load balance constraint. The total generated power must be sufficient to meet the load demand at all times, i.e.,

$$
\sum_{i=1}^{N} P_{i h} X_{i h} \geqslant D_{h}
$$

where $D_{h}$ is the load demand at time $h$.

2) Spinning reserve constraint. The spinning reserve is defined as the total amount of power generated by all of the synchronized units minus the present load plus any losses. In solving the UC problem, the value of the spinning reserve is either assigned a pre-determined value or is defined as a given percentage of the forecast peak demand. Clearly, the reserve must be sufficient to cover the loss of the most heavily loaded unit in the system. In other words, the spinning reserve constraint can be formulated as

$$
\sum_{i=1}^{N} X_{i h} * P_{i}(\max ) \geqslant D_{h}+R_{h}
$$

where $P_{i}(\max )$ maximum generation limit of unit $i ; R_{h}$ spinning reserve at time $h$.

3) Generation limit constraint. The generation of each unit must satisfy the following condition:

$$
P_{i}(\min ) \leqslant P_{i h} \leqslant P_{i}(\max )
$$


where $P_{i}(\min )$ minimum generation limit of unit $i$.

4) Thermal constraints. The temperature and pressure conditions of the different thermal units vary slightly and therefore the units must be synchronized before they are brought online. The thermal constraints are related primarily to the minimum uptime of each generating unit, the minimum downtime of each unit, and maintenance crew availability, respectively.

a) Minimum uptime. Once the unit is commissioned there is a minimum time before it can be decommissioned (i.e., a unit must be $\mathrm{ON}$ for a certain number of hours before it can be shut off).

b) Minimum downtime. Once the unit is de-committed there is a minimum time before it can be re-commissioned (i.e., a unit must be OFF for a certain number of hours before it can be brought online).

c) Maintenance crew availability. Since power plants have only limited maintenance crew resources, the simultaneous start-up and/or shutdown of two or more units is generally not possible. In solving the UC optimization problem, the effect of this resource constraint is modeled by specifying appropriate values for the times required to bring each unit online and to shut it down, respectively.

\section{Improved Differential Evolution (IDE) Method for Unit Commitment Problem}

In solving the UC problem, two types of variables must be considered, namely the units' status variables $X$, which are integer variables, and the units' output power variables $P$, which are continuous variables. The problem can therefore be decomposed into two separate sub-problems, i.e., a combinatorial problem in $X$ and a nonlinear optimization problem in $P$. In previous studies, the DE scheme was successfully applied to solve optimization problems (e.g., Storn and Price, 1996; Price, 1997), while the HDE method was used to solve both optimal control problems (e.g., Chiou and Wang, 1998) and nonlinear optimization problems (e.g., Lin et al., 1999). The current study develops an improved differential evolution (IDE) method in which the migration and acceleration operations of the original DE and HDE schemes are enhanced in order to restrict the size of the searched population. As a result, the proposed IDE scheme is particularly suited to the solution of large-scale combinatorial optimization problems such as that considered in the present study. The basic operations of the DE, HDE and IDE schemes are summarized in Table 1.

The details of the IDE method are presented in the sections below.

\subsection{Representation of Individual}

When applying the IDE method to solve a combinatorial optimization problem, the first step is to generate an initial population of candidate solutions, in which each candidate is defined in terms of the decision variables of the problem. The most simple and direct method for generating the initial population of solutions is to employ the UC reservation 
Table 1

Basic operations of DE, HDE and IDE schemes

\begin{tabular}{lll}
\hline DE & HDE & IDE \\
\hline 1. Initialization & 1. Initialization & 1. Initialization \\
2. Mutation & 2. Migration operation (if necessary) & 2. Mutation \\
3. Crossover & 3. Mutation & 3. Crossover \\
4. Estimation and selection & 4. Crossover & 4. Estimation and selection \\
5. Repeat Steps 2 to 4 & 5. Estimation and selection & 5. Accelerated operation (if necessary) \\
& 6. Repeat Steps 2 to 5 & 6. Migration operation (if necessary) \\
& & 7. Repeat Steps 2 to 6 \\
\hline
\end{tabular}

decision matrix shown in Fig. 1. As shown, the elements of this matrix represent the status variables of the various units, i.e., $X_{i h}$, where $X_{i h}=1$ indicates that unit $i$ is ON at time $h$, while $X_{i h}=0$ indicates that unit $i$ is OFF at time $h$. Furthermore, $N$ corresponds to the total number of generating units in the system, while $H$ indicates the total number of hours in the scheduling time frame. However, as described in Section 2, each generating unit is subject to certain minimum uptime and downtime constraints, i.e., $T_{i}^{\text {up }}$ and $T_{i}^{\text {down }}$, respectively, and clearly these constraints must be satisfied when populating the initial search space. Consequently, the candidate solutions are defined in the form of the UC decision matrix presented in Fig. 2.

In Fig. 2, each row describes the status transitions of a particular generating unit and indicates the number of hours for which the unit remains in each state. As shown, the entries in each row are divided into a series of sub-strings, i.e., $Y_{i 1}, Y_{i 2}, Y_{i 3}, Y_{i 4}$, and so forth. Each sub-string defines the ON or OFF status of a unit for a particular number of hours in the scheduling horizon. Therefore, taken sequentially, the sub-strings describe the alternation of the unit between the $\mathrm{ON}$ and OFF states over the entire scheduling time frame. As shown, each sub-string comprises four bits. The first bit represents the ON/OFF status of the unit (where 1 is $\mathrm{ON}$ and 0 is $\mathrm{OFF}$ ), while the following three bits indicate the duration in hours for which the unit remains in the state specified by the leading

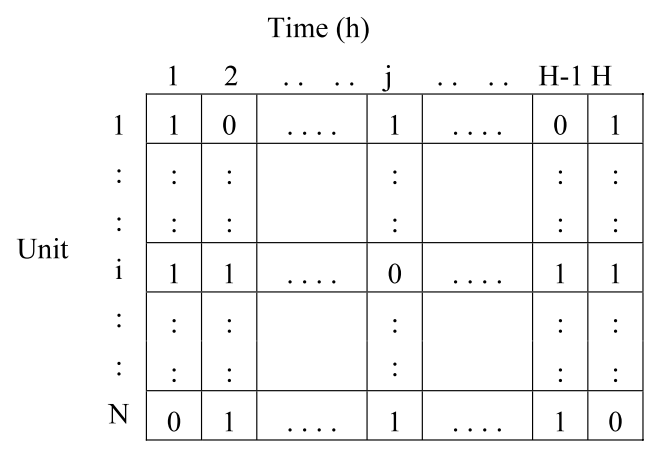

Fig. 1. Unit commitment reservation decision matrix. 


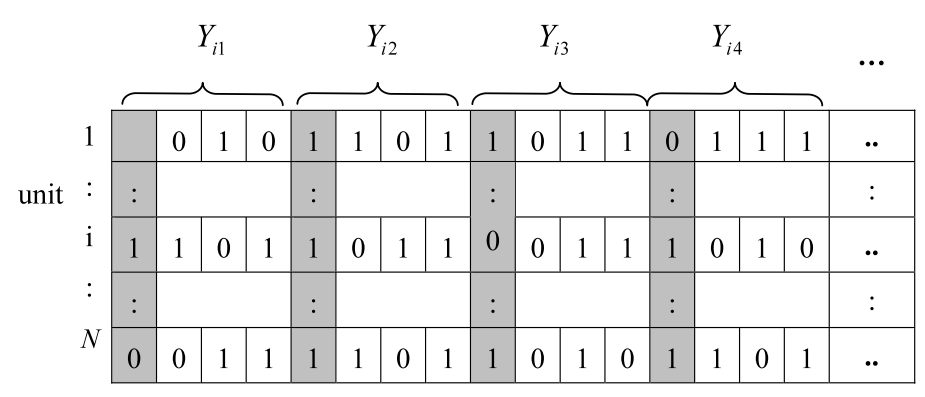

Fig. 2. Unit commitment decision matrix.

bit. The total duration for which the state of the unit remains unchanged is based upon the specified values of the minimum uptime and downtime constraints. For example, if $T_{i}^{\mathrm{up}}=2$ and $T_{i}^{\text {down }}=3$, the sub-string $Y_{i 2}=1 \mid 011$ indicates that unit $i$ is continuously ON for 5 hours, while sub-string $Y_{i 3}=0 \mid 011$ indicates that unit $i$ is continuously OFF for 6 hours.

\subsection{Fitness Function}

In the IDE method, the suitability of each UC decision matrix as a candidate solution for the UC problem is evaluated using a fitness function of the form

$$
f_{p_{j}}=\frac{1}{\Phi_{p_{j}} \sum_{h=1}^{H} \lambda_{h} * p f},
$$

where $\Phi_{p_{i}}$ is the production cost function associated with $p_{i}$; $h$ is the time index; $H$ is the total number of hours in the UC scheduling horizon; $\lambda_{h}$ is the constraint constant and has a value of 1 if the constraints are not satisfied and a value of 0 otherwise; and $p f$ is the penalty factor. The penalty factor is provided for the identification of the individual $p_{i}$ on the constraint is satisfied or dissatisfied.

In practice, the value of the fitness function is normalized between 0 and 1, i.e.,

$$
\Gamma_{p_{i}}=\frac{1}{1+K\left(\frac{f_{\max }}{f_{p_{i}}}-1\right)},
$$

where $K$ is a scaling coefficient and $f_{\max }$ is the maximum value of $f_{p_{i}}$ within the current population.

\subsection{Main Operations in IDE Solution of UC Problem}

The general DE algorithm is described in Storn and Price (1996), Price (1997), Storn (1999), while the HDE scheme is well documented in Chiou and Wang (1998). Hence, the details of these two schemes are omitted here. The IDE method proposed in 
the present study employs a population $S_{p}$ of size $N P$ composed of floating pointencoded individuals which converge over $G$ generations towards the optimal solution, $S_{p}^{(G)}=\left[\bar{P}_{1}^{(G)}, \bar{P}_{2}^{(G)}, \ldots, \bar{P}_{N P}^{(G)}\right]$, in which each $\bar{P}_{i}$ is a vector containing as many parameters as there are decision variables $D$ in the problem, i.e., $N * H$ (see Fig. 2) and $\bar{P}_{i}^{(G)}=\left[P_{1, i}^{(G)}, P_{2, i}^{(G)}, \ldots, P_{D, i}^{(G)}\right]^{T}, i=1,2, \ldots, N P$. Note that the population size parameter, $N P$, is specified by the user and remains constant throughout the optimization process. As described in the following, the IDE algorithm contains seven major operations.

1) Initialization. An initial population of $N P$ vectors is created for the algorithm stats In order to obtain a uniform coverage of the entire parameter space, the random variables are assumed to conform to a uniform probability distribution, i.e.,

$$
P_{j, i}^{(0)}=P_{j}^{\min }+\mu\left(P_{j}^{\max }-P_{j}^{\min }\right)
$$

where $i=1,2, \ldots, N P$ and $j=1,2, \ldots, D ; P_{j}^{\min }$ and $P_{j}^{\max }$ are the lower and upper bounds of the $j$ th decision parameter; and $u \in[0,1]$ is randomly selected from a uniform distribution and is generated afresh for each value of $j$.

2) Mutation. The mutation operation creates mutant vectors $\left(\bar{P}_{i}^{M}\right)$ by perturbing a randomly selected vector $\left(\bar{P}_{\alpha}\right)$ with the difference between two other randomly selected vectors $\left(\bar{P}_{\beta}\right.$ and $\left.\bar{P}_{\gamma}\right)$, i.e.,

$$
{\overline{P_{i}}}^{M(G)}=\bar{P}_{\alpha}^{(G)}+F\left(\bar{P}_{\beta}^{(G)}-\bar{P}_{\gamma}^{(G)}\right),
$$

where $\bar{P}_{\alpha}, \bar{P}_{\beta}$ and $\bar{P}_{\gamma}$ are randomly chosen vectors with $\alpha \neq \beta \neq \gamma \neq i$ and are selected afresh for each parent vector. The mutation scaling factor $(F \in(0,2])$ is used to adjust the perturbation size in the mutation operation in order to improve the convergence of the search procedure. In general, the DE family of optimization schemes offers several variants or strategies for the solution of practical optimization problems. These strategies can be annotated as $\mathrm{DE} / x / y / z$, where $x$ refers to the vector used to generate the mutant vectors, $y$ is the number of difference vectors used in the mutation process, and $z$ is the scheme applied to perform the crossover operation. The most commonly employed DE strategy for global optimization problems is the DE/best/2/bin variant, which perturbs the best solution found to date with two difference vectors in accordance with a binomial distribution crossover scheme, i.e.,

$$
{\overline{P_{i}}}^{M(G)}=\bar{P}_{\text {best }}+F\left(\bar{P}_{a}^{(G)}-\bar{P}_{b}^{(G)}+\bar{P}_{c}^{(G)}-\bar{P}_{d}^{(G)}\right)
$$

where $\bar{P}_{\text {best }}$ is the best solution found to date in the optimization process and $\bar{P}_{a}, \bar{P}_{b}, \bar{P}_{c}$ and $\bar{P}_{d}$ are randomly chosen vectors with $a \neq b \neq c \neq d \neq i$ and are selected anew for each parent vector.

3) Crossover. The crossover operation generates trial vectors $\left(\bar{P}_{i}^{C}\right)$ by mixing the parameters of the mutant vectors $\left(\bar{P}_{i}^{M}\right)$ produced in Step 2 above with the target vec- 
tors $\left(\bar{P}_{i}\right)$ in accordance with a specified probability distribution, i.e.,

$$
\bar{P}_{j, i}^{C(G)}= \begin{cases}\bar{P}_{j, i}^{M(G)}, & \text { if } \mu_{c} \leqslant C_{r} \text { or } j=k \\ \bar{P}_{j, i}^{(G)}, & \text { otherwise }\end{cases}
$$

where $i=1,2, \ldots, N P$ and $j=1,2, \ldots, D ; k$ is a randomly chosen index which guarantees that the trial vector receives at least one parameter from the mutant vector; and $\mu_{c} \in[0,1)$ is a uniformly distributed random number generated afresh for each value of $j$. The crossover constant, i.e., $C_{r} \in[0,1]$, controls the diversity of the population and prevents the algorithm from converging prematurely to local optima. Finally, $\bar{P}_{j, i}^{(G)}, \bar{P}_{j, i}^{M(G)}$ and $\bar{P}_{j, i}^{C(G)}$ are the $j$ th parameters of the $i$ th target vector, the mutant vector, and the trial vector, respectively, in the $G$ th generation.

4) Estimation and selection. During the IDE iterative procedure, the parents are replaced by their offspring if the fitness (i.e., the total production cost in the current problem) of the offspring exceeds that of its parents. Conversely, if the parents have a better fitness than their offspring, they are retained within the next generation, and the offspring is rejected. This procedure can be formulated as

$$
\bar{P}_{i}^{(G+1)}= \begin{cases}\bar{P}_{i}^{M(G)}, & \text { if } \Phi\left(\bar{P}_{i}^{M(G)}\right) \leqslant \Phi\left(\bar{P}_{i}^{(G)}\right), \\ \bar{P}_{i}^{(G)}, & \text { otherwise, }\end{cases}
$$

5) Acceleration operation (if required). If the best fitness of the solutions in the present generation is not improved by the mutation and crossover operations, the best of the present individuals is artificially pushed toward a better point in accordance with

$$
\bar{P}_{\text {best }}^{(G+1)}= \begin{cases}\bar{P}_{\text {best }}^{(G+1)}, & \text { if } \Phi\left(\bar{P}_{\text {best }}^{(G+1)}\right)<\Phi\left(\bar{P}_{\text {best }}^{(N)}\right), \\ \bar{P}_{\text {best }}^{(G+1)}-\left.d_{z} \nabla P \Phi(\bar{P})\right|_{\bar{P}_{\text {best }}^{(G+1)}}, & \text { otherwise }\end{cases}
$$

where $\bar{P}_{\text {best }}^{(G+1)}$ represents the new best solution. Note that the gradient of the objective function $\nabla P \Phi(\bar{P})$ in Eq. (13) can be calculated with finite variation. Furthermore, the step size $d_{z} \in[0,1]$ is determined according to the descent property. If the descent property is satisfied, and if $\Phi\left(\bar{P}_{\text {best }}^{(N)}\right)$ is less than $\Phi\left(\bar{P}_{\text {best }}^{(G+1)}\right)$, then $\bar{P}_{\text {best }}^{(N)}$ is transcribed directed into the next generation in place of the weakest individual in the current generation..

6) Migration operation (if required). If the best fitness of the solutions in the present generation is not improved by acceleration operations, the migration operation is performed to regenerate a newly diverse population of individuals in order to enhance the thoroughness with which the solution space is searched and therefore to make possible the use of a smaller population size than that used in the conventional DE and HDE schemes. The new population is based on the best individual $\bar{P}_{\text {best }}^{(G+1)}$, with the $h$ th gene 
of the $i$ th individual given by

$$
P_{h, i}^{(G+1)}= \begin{cases}P_{h, i}^{(G+1)}+\rho_{1}\left(P_{h, \min }-P_{h, \text { best }}^{(G+1)}\right), & \text { if } \rho_{2}<\frac{P_{h, i}^{(G+1)}-P_{h, \min }}{P_{h, \max }-P_{h, \min }} \\ P_{h, i}^{(G+1)}+\rho_{1}\left(P_{h, \max }-P_{h, \text { best }}^{(G+1)}\right), & \text { otherwise },\end{cases}
$$

where $P_{h, \min }$ and $P_{h, \max }$ are the minimum and maximum individuals at time $h$, respectively; $P_{h, \text { best }}^{(G+1)}$ is the best individual of the new generation at time $h$; and $\rho_{1}$ and $\rho_{2}$ are randomly generated numbers uniformly distributed in the range $[0,1]$.

7) Termination criterion. The iterative IDE solution procedure terminates if either the number of iterations performed since the best solution last changed exceeds a specified value or if the maximum specified number of iterations have been completed. If the termination criteria are not satisfied, the solution procedure returns to Step 2 and the processing steps described above are repeated.

\section{Performance Evaluation Results}

In this study, the performance of the IDE scheme is demonstrated using the Tai-Power System (TPS) for illustration purposes. The basic parameters of this system are summarized in Table 2. Overall, TPS includes 305 buses, 506 lines, 62 generators, 151 transformers, and 40 thermal generating units.

In solving the current UC problem, the scheduling horizon is assumed to be $24 \mathrm{~h}$. The minimum and maximum permissible power generation limits of each unit are summarized in Table 2 together with the corresponding cost function parameters. The minimum up-time and down-time constraints of each unit are also shown. In general, the aim of the IDE scheme is to determine the status of each unit $i$ at each time index $h$ such that the total operating cost of TPS is minimized over the scheduling horizon while simultaneously satisfying the power generation limits and up-time/down-time constraints specified in Table 2. In the current study, the IDE scheme is implemented using $\mathrm{C}++($ Press and Teuko, 2002) and the UC solution procedure is executed on a personal computer (PCD32mPentiumIV-2.4G). The IDE simulation parameters are summarized in Table 3. The IDE results for the TPS UC problem are summarized in Table 4.

\subsection{Performance Tests}

Having demonstrated the ability of the IDE method to solve the complex, large-scale TPS UC problem, its potential for solving general UC-type problems was evaluated by benchmarking its performance against that of other optimization schemes presented in the literature, including the DP and BB deterministic approaches and the SA and GA meta-heuristic approaches, respectively. Tables 5 and 6 present typical examples of the benchmarking results. Table 5 shows the case where the IDE scheme and the DP scheme are applied to solve the UC problem for a power system comprising ten generating units. 
Table 2

Unit data of Tai-Power System (TPS)

\begin{tabular}{|c|c|c|c|c|c|c|c|c|}
\hline \multirow[t]{2}{*}{ Unit } & \multirow{2}{*}{$\begin{array}{l}P_{i}(\max ) \\
(\mathrm{MW})\end{array}$} & \multirow{2}{*}{$\begin{array}{l}P_{i}(\min ) \\
(\mathrm{MW})\end{array}$} & \multicolumn{3}{|c|}{ Cost function coefficients } & \multirow[t]{2}{*}{$S T C_{i}$} & \multirow{2}{*}{$\begin{array}{l}T_{i}^{\mathrm{up}} \\
\text { (h) }\end{array}$} & \multirow{2}{*}{$\begin{array}{l}T_{i}^{\text {down }} \\
\text { (h) }\end{array}$} \\
\hline & & & $\begin{array}{l}c_{i} \\
\left(\$ / \mathrm{MW}^{2} \mathrm{~h}\right)\end{array}$ & $\begin{array}{l}b_{i} \\
\left(\$ / \mathrm{MW}^{2} \mathrm{~h}\right)\end{array}$ & $\begin{array}{l}a_{i} \\
(\$ / \mathrm{h})\end{array}$ & & & \\
\hline 1 & 80 & 40 & 170.4 & 8.336 & 0.0307 & 247.396 & 2 & 3 \\
\hline 2 & 120 & 60 & 309.5 & 7.0706 & 0.0202 & 248.107 & 2 & 3 \\
\hline 3 & 190 & 80 & 369.0 & 8.1817 & 0.0094 & 245.837 & 2 & 3 \\
\hline 4 & 42 & 24 & 135.4 & 6.9467 & 0.0848 & 246.244 & 2 & 3 \\
\hline 5 & 42 & 26 & 135.1 & 6.5595 & 0.0969 & 231.796 & 2 & 3 \\
\hline 6 & 140 & 68 & 222.3 & 8.0543 & 0.0114 & 267.588 & 2 & 3 \\
\hline 7 & 300 & 110 & 28737 & 8.0323 & 0.0035 & 267.007 & 2 & 3 \\
\hline 8 & 300 & 135 & 391.9 & 6.999 & 0.0049 & 326.660 & 2 & 3 \\
\hline 9 & 300 & 135 & 455.7 & 6.602 & 0.0057 & 267.629 & 2 & 3 \\
\hline 10 & 300 & 130 & 722.8 & 12.908 & 0.0060 & 376.284 & 2 & 3 \\
\hline 11 & 375 & 94 & 635.2 & 12.986 & 0.0051 & 383.911 & 2 & 3 \\
\hline 12 & 375 & 94 & 654.6 & 12.796 & 0.0056 & 384.018 & 2 & 3 \\
\hline 13 & 500 & 125 & 913.4 & 12.501 & 0.0042 & 384.024 & 2 & 3 \\
\hline 14 & 500 & 125 & 1760 & 8.8412 & 0.0075 & 380.379 & 2 & 3 \\
\hline 15 & 500 & 125 & 1728 & 9.1575 & 0.0070 & 386.993 & 2 & 3 \\
\hline 16 & 500 & 125 & 1728 & 9.1575 & 0.0070 & 380.003 & 2 & 3 \\
\hline 17 & 500 & 125 & 1728 & 9.1575 & 0.0070 & 247.396 & 2 & 3 \\
\hline 18 & 500 & 220 & 647.8 & 7.9691 & 0.0031 & 248.107 & 2 & 3 \\
\hline 19 & 500 & 220 & 649.6 & 7.9550 & 0.0031 & 245.837 & 2 & 3 \\
\hline 20 & 550 & 242 & 647.8 & 7.9691 & 0.0031 & 246.244 & 2 & 3 \\
\hline 21 & 550 & 242 & 647.8 & 7.9691 & 0.0031 & 231.796 & 2 & 3 \\
\hline 22 & 550 & 254 & 758.9 & 6.6313 & 0.0029 & 267.588 & 2 & 3 \\
\hline 23 & 550 & 254 & 758.9 & 6.6313 & 0.0029 & 267.007 & 2 & 3 \\
\hline 24 & 550 & 254 & 794.5 & 6.6611 & 0.0028 & 326.660 & 2 & 3 \\
\hline 25 & 550 & 254 & 794.5 & 6.6611 & 0.0028 & 267.269 & 2 & 3 \\
\hline 26 & 550 & 254 & 801.3 & 7.1032 & 0.0027 & 376.284 & 2 & 3 \\
\hline 27 & 550 & 254 & 801.3 & 7.1032 & 0.0027 & 383.911 & 2 & 3 \\
\hline 28 & 150 & 10 & 1055 & 3.3353 & 0.5212 & 384.018 & 2 & 3 \\
\hline 29 & 150 & 10 & 1055 & 3.3353 & 0.5212 & 384.024 & 2 & 3 \\
\hline 30 & 150 & 10 & 1055 & 3.3353 & 0.5212 & 380.379 & 2 & 3 \\
\hline 31 & 70 & 20 & 1207 & 13.052 & 0.2509 & 386.993 & 2 & 3 \\
\hline 32 & 70 & 20 & 810.7 & 21.887 & 0.1676 & 380.003 & 2 & 3 \\
\hline 33 & 70 & 20 & 1247 & 10.244 & 0.2635 & 267.629 & 2 & 3 \\
\hline 34 & 70 & 20 & 1219 & 8.3707 & 0.3057 & 376.284 & 2 & 3 \\
\hline 35 & 60 & 18 & 641.4 & 26.258 & 0.1836 & 383.911 & 2 & 3 \\
\hline 36 & 60 & 18 & 1112 & 9.6956 & 0.3256 & 384.018 & 2 & 3 \\
\hline 37 & 60 & 20 & 1044 & 7.1633 & 0.3372 & 384.024 & 2 & 3 \\
\hline 38 & 60 & 25 & 832.2 & 16.339 & 0.2391 & 380.379 & 2 & 3 \\
\hline 39 & 60 & 25 & 834.2 & 16.339 & 0.2391 & 386.993 & 2 & 3 \\
\hline 40 & 60 & 25 & 1035 & 16.339 & 0.2391 & 380.003 & 2 & 3 \\
\hline
\end{tabular}


Table 3

Simulation parameters used in IDE solution procedure

\begin{tabular}{lll}
\hline Parameters & Symbols & Value \\
\hline Decision variables & $D(N * H)$ & $40 * 24$ \\
Scaling coefficient & $K$ & 1000 \\
Population size & $N P$ & 80 \\
Mutation scaling factor & $F \in(0,2]$ & 1.2 \\
Crossover constant & $C_{r} \in[0,1]$ & 0.5 \\
Accelerated step size & $d_{z} \in[0,1]$ & 0.2 \\
Migration coefficient & $\rho_{1} \in[0,1]$ & 0.1 \\
& $\rho_{2} \in[0,1]$ & 0.1 \\
Maximum generations & $G_{\max }$ & 120 \\
\hline
\end{tabular}

It is observed that the total operating cost obtained by the IDE scheme is lower than that obtained by the DP scheme; hence confirming the effectiveness of the proposed approach. Table 6 presents the total costs obtained by the IDE scheme and the BB method for power systems with 10 and 20 generating units over a scheduling horizon of 24 hours and 36 hours, respectively. In both cases, it can be seen that the IDE scheme achieves a lower operating cost.

In meta-heuristic approaches, SA is a general-purpose stochastic optimization technique which theoretically converges asymptotically to a global optimum solution with a probability of 1 . GAs are a general-purpose stochastic, parallel search method based on the "survival-of-the-fittest" mechanisms inherent in biological evolutionary processes which have the ability to obtain near-global optimal solutions to complex optimization problems with various conflicting objectives within a reasonably short processing time. Therefore, the performance of the IDE scheme in solving the TPS UC problem was compared with that of the stochastic SA and GA schemes in terms of: (1) the solution quality, i.e., the total production cost; (2) the convergence speed, i.e., the CPU time required to complete 120 generations; and (3) the stability, i.e., the number of best solutions from 100 test runs. The corresponding results are presented in Table 7. (Note that the same set of random initial solutions and the same population size were used in all three schemes).

It is clear from Table 7 that the proposed IDE yields a better solution than the SA and GA schemes in the best, average and worst costs. The computational time for the proposed IDE is lower than the time for the SA and GA approaches, and the IDE has a better stability than the GA. From the comparing, it is obvious that the IDE is a reliable algorithm, resulting in a cheaper computational cost and faster speed of convergence.

\subsection{Scalability of IDE Scheme}

The performance of the IDE scheme was further analyzed by comparing its total cost solutions for power systems comprising 10, 20, 40, 60 and 80 generating units, respectively, over a 24 hour horizon with those computed by Kazarlis et al. (1996) using a GA. The corresponding results are presented in Table 8 . 
Table 4

IDE solutions for TPS UC problem

\begin{tabular}{|c|c|c|c|c|c|c|c|c|c|c|c|c|c|c|c|c|c|c|c|c|c|c|c|c|c|}
\hline \multirow[t]{2}{*}{ Unit } & \multicolumn{25}{|c|}{$H$} \\
\hline & 0 & 1 & 2 & 3 & 4 & 5 & 6 & 7 & 8 & 9 & 10 & 11 & 12 & 13 & 14 & 15 & 16 & 17 & 18 & 19 & 20 & 21 & 22 & 23 & 24 \\
\hline 1 & 1 & 1 & 1 & 1 & 1 & 1 & 1 & 1 & 1 & 1 & 1 & 1 & 1 & 1 & 1 & 1 & 1 & 1 & 1 & 1 & 1 & 1 & 1 & 1 & 1 \\
\hline 2 & 1 & 1 & 1 & 1 & 1 & 1 & 1 & 1 & 1 & 1 & 1 & 1 & 1 & 1 & 1 & 1 & 1 & 1 & 1 & 1 & 1 & 1 & 1 & 0 & 0 \\
\hline 3 & 0 & 0 & 0 & 0 & 0 & 0 & 0 & 0 & 0 & 1 & 1 & 1 & 1 & 1 & 1 & 0 & 0 & 0 & 0 & 0 & 1 & 1 & 1 & 1 & 1 \\
\hline 4 & 0 & 0 & 0 & 0 & 0 & 0 & 0 & 0 & 1 & 1 & 1 & 1 & 1 & 1 & 1 & 1 & 1 & 1 & 1 & 1 & 1 & 1 & 1 & 1 & 1 \\
\hline 5 & 0 & 0 & 0 & 1 & 1 & 1 & 1 & 1 & 1 & 1 & 1 & 1 & 1 & 1 & 1 & 1 & 1 & 1 & 1 & 1 & 1 & 1 & 0 & 0 & 0 \\
\hline 6 & 0 & 0 & 0 & 0 & 0 & 0 & 0 & 0 & 0 & 1 & 1 & 1 & 1 & 1 & 1 & 1 & 0 & 0 & 0 & 0 & 1 & 1 & 1 & 1 & 1 \\
\hline 7 & 0 & 0 & 0 & 0 & 0 & 0 & 0 & 0 & 0 & 0 & 0 & 1 & 1 & 1 & 1 & 0 & 0 & 0 & 0 & 0 & 0 & 0 & 0 & 0 & 0 \\
\hline 8 & 0 & 0 & 0 & 0 & 0 & 0 & 0 & 0 & 0 & 0 & 0 & 1 & 1 & 0 & 0 & 0 & 0 & 0 & 0 & 0 & 1 & 0 & 0 & 0 & 0 \\
\hline 9 & 0 & 0 & 0 & 0 & 0 & 0 & 0 & 0 & 0 & 0 & 0 & 1 & 1 & 1 & 0 & 0 & 0 & 0 & 0 & 0 & 1 & 0 & 0 & 0 & 0 \\
\hline 10 & 0 & 0 & 0 & 0 & 0 & 0 & 0 & 0 & 0 & 0 & 0 & 1 & 1 & 0 & 0 & 0 & 0 & 0 & 0 & 0 & 1 & 0 & 0 & 0 & 0 \\
\hline 11 & 1 & 1 & 1 & 1 & 1 & 1 & 1 & 1 & 1 & 1 & 1 & 1 & 1 & 1 & 1 & 1 & 1 & 1 & 1 & 1 & 1 & 1 & 1 & 1 & 1 \\
\hline 12 & 1 & 1 & 1 & 1 & 1 & 1 & 1 & 1 & 1 & 1 & 1 & 1 & 1 & 1 & 1 & 1 & 1 & 1 & 1 & 1 & 1 & 1 & 1 & 1 & 1 \\
\hline 13 & 0 & 0 & 0 & 0 & 1 & 0 & 1 & 1 & 1 & 1 & 1 & 1 & 1 & 1 & 0 & 0 & 0 & 1 & 0 & 1 & 1 & 1 & 1 & 1 & 1 \\
\hline 14 & 0 & 0 & 0 & 0 & 1 & 1 & 1 & 1 & 1 & 1 & 1 & 1 & 1 & 1 & 1 & 1 & & 1 & 1 & 1 & 1 & 1 & 1 & 0 & 0 \\
\hline 15 & 0 & 0 & 0 & 0 & 0 & 1 & 1 & 1 & 1 & 1 & 1 & 1 & 1 & 1 & 1 & 1 & 1 & 1 & 1 & 1 & 1 & 1 & 0 & 0 & 0 \\
\hline 16 & 0 & 0 & 0 & 0 & 0 & 0 & 0 & 0 & 1 & 1 & 1 & 1 & 1 & 1 & 1 & 1 & 0 & 0 & 0 & 1 & 1 & 1 & 1 & 1 & 1 \\
\hline 17 & 0 & 0 & 0 & 0 & 0 & 0 & 0 & 0 & 0 & 1 & 1 & 1 & 1 & 1 & 0 & 0 & 0 & 0 & 0 & 1 & 1 & 1 & 0 & 0 & 0 \\
\hline 18 & 0 & 0 & 0 & 0 & 0 & 0 & 0 & 0 & 0 & 0 & 1 & 0 & 1 & 0 & 0 & 0 & 0 & 0 & 0 & 0 & 0 & 0 & 0 & 0 & 0 \\
\hline 19 & 0 & 0 & 0 & 0 & 0 & 0 & 0 & 0 & 0 & 0 & 1 & 0 & 1 & 0 & 0 & 0 & 0 & 0 & 0 & 0 & 1 & 0 & 0 & 0 & 0 \\
\hline 20 & 0 & 0 & 0 & 0 & 0 & 0 & 0 & 0 & 0 & 0 & 0 & 0 & 1 & 0 & 0 & 0 & 0 & 0 & 0 & 0 & 0 & 0 & 0 & 0 & 0 \\
\hline 21 & 1 & 1 & 1 & 1 & 1 & 1 & 1 & 1 & 1 & 1 & 1 & 1 & 1 & 1 & 1 & 1 & 1 & 1 & 1 & 1 & 1 & 1 & 1 & 1 & 1 \\
\hline 22 & 1 & 1 & 1 & 1 & 1 & 1 & 1 & 1 & 1 & 1 & 1 & 1 & 1 & 1 & 1 & 1 & 1 & 1 & 1 & 1 & 1 & 1 & 1 & 1 & 1 \\
\hline 23 & 0 & 0 & 0 & 0 & 0 & 0 & 1 & 1 & 1 & 1 & 1 & 1 & 1 & 1 & 1 & 1 & 1 & 1 & 1 & 1 & 1 & 1 & 1 & 1 & 1 \\
\hline 24 & 0 & 0 & 0 & 0 & 0 & 1 & 1 & 1 & 1 & 1 & 1 & 1 & 1 & 1 & 1 & 1 & 1 & 1 & 1 & 1 & 1 & 1 & 0 & 0 & 0 \\
\hline 25 & 0 & 0 & 0 & 1 & 1 & 1 & 1 & 1 & 1 & 1 & 1 & 1 & 1 & 1 & 1 & 1 & 1 & 1 & 1 & 1 & 1 & 1 & 0 & 0 & 0 \\
\hline 26 & 0 & 0 & 0 & 0 & 0 & 0 & 0 & 0 & 0 & 0 & 1 & 1 & 1 & 1 & 1 & 1 & 0 & 0 & 0 & 0 & 1 & 1 & 1 & 0 & 0 \\
\hline 27 & 0 & 0 & 0 & 0 & 0 & 0 & 0 & 0 & 0 & 0 & 1 & 1 & 1 & 1 & 0 & 0 & 0 & 0 & 0 & 1 & 1 & 1 & 0 & 0 & 0 \\
\hline 28 & 0 & 0 & 0 & 0 & 0 & 0 & 0 & 0 & 0 & 0 & 0 & 1 & 1 & 0 & 0 & 0 & 0 & 0 & 0 & 0 & 1 & 0 & 0 & 0 & 0 \\
\hline 29 & 0 & 0 & 0 & 0 & 0 & 0 & 0 & 0 & 0 & 0 & 1 & 1 & 1 & 0 & 0 & 0 & 0 & 0 & 0 & 0 & 1 & 0 & 0 & 0 & 0 \\
\hline 30 & 0 & 0 & 0 & 0 & 0 & 0 & 0 & 0 & 0 & 0 & 1 & 1 & 1 & 1 & 0 & 0 & 0 & 0 & 0 & 0 & 1 & 0 & 0 & 0 & 0 \\
\hline 31 & 1 & 1 & 1 & 1 & 1 & 1 & 1 & 1 & 1 & 1 & 1 & 1 & 1 & 1 & 1 & 1 & 1 & 1 & 1 & 1 & 1 & 1 & 1 & 1 & 1 \\
\hline 32 & 1 & 1 & 1 & 1 & 1 & 1 & 1 & 1 & 1 & 1 & 1 & 1 & 1 & 1 & 1 & 1 & 1 & 1 & 1 & 1 & 1 & 1 & 1 & 1 & 1 \\
\hline 33 & 0 & 0 & 0 & 0 & 0 & 0 & 0 & 1 & 1 & 1 & 1 & 1 & 1 & 1 & 1 & 0 & 0 & 0 & 0 & 0 & 1 & 1 & 1 & 1 & 1 \\
\hline 34 & 0 & 0 & 0 & 0 & 0 & 0 & 1 & 1 & 1 & 1 & 1 & 1 & 1 & 1 & 1 & 1 & 1 & 1 & 1 & 1 & 1 & 1 & 0 & 0 & 0 \\
\hline 35 & 0 & 0 & 0 & 0 & 1 & 1 & 1 & 1 & 1 & 1 & 1 & 1 & 1 & 1 & 1 & 1 & 1 & 1 & 1 & 1 & 1 & 1 & 1 & 0 & 0 \\
\hline 36 & 0 & 0 & 0 & 0 & 0 & 0 & 0 & 0 & 1 & 1 & 1 & 1 & 1 & 1 & 1 & 0 & 0 & 0 & 0 & 0 & 1 & 1 & 1 & 0 & 0 \\
\hline 37 & 0 & 0 & 0 & 0 & 0 & 0 & 0 & 0 & 0 & 0 & 1 & 1 & 1 & 1 & 1 & 1 & 0 & 0 & 0 & 0 & 0 & 0 & 0 & 0 & 0 \\
\hline 38 & 0 & 0 & 0 & 0 & 0 & 0 & 0 & 0 & 0 & 0 & 1 & 1 & 1 & 0 & 1 & 0 & 0 & 0 & 0 & 0 & 0 & 0 & 0 & 0 & 0 \\
\hline 39 & 0 & 0 & 0 & 0 & 0 & 0 & 0 & 0 & 0 & 0 & 1 & 1 & 1 & 1 & 0 & 1 & 0 & 0 & 0 & 0 & 0 & 0 & 0 & 0 & 0 \\
\hline 40 & 0 & 0 & 0 & 0 & 0 & 0 & 0 & 0 & 0 & 0 & 0 & 0 & 1 & 1 & 0 & 0 & 0 & 0 & 0 & 0 & 0 & 0 & 0 & 0 & 0 \\
\hline
\end{tabular}

Table 5

Performance of IDE and DP schemes in solving UC problem for power system presented in Snyder et al. (1987)

\begin{tabular}{lll}
\hline Method & IDE & DP \\
\hline Total cost (\$) of 10-unit system over 24 H & 562,921 & 565,125 \\
\hline
\end{tabular}


Table 6

Performance of IDE and BB schemes in solving UC problem for power systems presented in Chen and Wang (1993)

\begin{tabular}{lrr}
\hline Method & \multicolumn{1}{l}{ IDE } & \multicolumn{1}{c}{ BB } \\
\hline Total cost (\$) of 10-unit system over 24 H & 78,020 & 78,907 \\
Total cost (\$) of 20-unit system over 36 H & 987,612 & $1,006,875$ \\
\hline
\end{tabular}

Table 7

Performance comparison between IDE, SA and GA schemes when applied to TPS UC problem

\begin{tabular}{llrrr}
\hline Method & & \multicolumn{1}{l}{ IDE } & \multicolumn{1}{l}{ SA } & \multicolumn{1}{l}{ GA } \\
\hline Total cost $(\$)$ & Best & $2,165,082$ & $2,266,657$ & $2,398,513$ \\
& Average & $2,169,950$ & $2,271,886$ & $2,401,426$ \\
& Worst & $2,177,062$ & $2,278,938$ & $2,416,727$ \\
CPU time (sec) & & 161 & 237 & 167 \\
Stability & & 0.99 & 0.99 & 0.98 \\
\hline
\end{tabular}

Table 8

Performance of IDE and GA schemes in solving UC problem for systems presented in Kazarlis et al. (1996)

\begin{tabular}{lrr}
\hline Method & \multicolumn{1}{c}{ IDE } & \multicolumn{1}{c}{ GA } \\
\hline Total cost (\$) of 10-unit system over 24 H & 562,921 & 563,825 \\
Total cost (\$) of 20-unit system over 24 H & $1,125,546$ & $1,129,555$ \\
Total cost (\$) of 40-unit system over 24 H & $2,247,570$ & $2,256,501$ \\
Total cost (\$) of 60-unit system over 24 H & $3,365,125$ & $3,392,065$ \\
Total cost (\$) of 80-unit system over 24 H & $4,486,010$ & $4,524,011$ \\
\hline
\end{tabular}

From inspection, it is clear that the IDE scheme consistently produces lower total cost solutions than the GA method. Furthermore, it is apparent that the cost savings achieved by the IDE scheme increase as the size of the power system increases. In other words, the IDE approach represents a particularly suitable technique for the solution of large-scale UC problems.

\section{Conclusion}

In general, the overriding objective of PPEs is to meet the time-varying power demands placed upon them while simultaneously minimizing their production costs. Satisfying this objective requires the solution of a highly complex unit commitment (UC) problem. To assist PPEs in performing this task, the current study has presented an improved differ- 
ential evolution (IDE) scheme designed to solve large-scale UC problems in a rapid and cost-effective manner. The performance of the proposed scheme has been benchmarked against that of other deterministic and stochastic optimization methods presented in the literature using the practical Tai-Power System (TPS) and various power systems of different scales for illustration purposes. The results have indicated that despite the comparatively small population size used in the proposed IDE scheme, the solutions obtained for the total operating costs of the various power systems are consistently better (i.e., lower) than those obtained by the other methods. Furthermore, the IDE scheme also outperforms the other schemes in terms of the CPU time required to complete the optimization procedure and the stability of the solutions, respectively. Finally, the results have indicated that the magnitude of the cost savings achieved by the IDE scheme increases as the number of generating units within the power system increases. In other words, the proposed scheme represents a particularly effective technique for the solution of large-scale UC problems.

\section{References}

Chen, C.L., Wang, M.C. (1993). Branch-and-bound scheduling for thermal generating units. IEEE Transactions on Energy Conversion, 8(2), 184-189.

Chiou, J.P., Wang, F.S. (1998). A hybrid method of differential evolution with application to optimal control problems of a bioprocess system. In: Proceedings IEEE Evolutionary Computation Conference, pp. 627632.

Dzemyda, G., Sakalauskas, L. (2009). Optimization and knowledge-based technologies. Informatica, 20(2), $165-172$.

Kazarlis, S.A., Bakirtzis, A.G., Petridis, V. (1996). A genetic algorithms solution to the unit commitment problem. IEEE Transactions on Power Systems, 11(1), 83-92.

Lin, Y.C., Hwang, K.S., Wang, F.S. (1999). A hybrid method of evolutionary algorithms for mixed-integer nonlinear optimization problems. In: Proceedings IEEE Evolutionary Computation Conference, pp. 21582166.

Mantawy, A.H., Youssef, L., Abdel-Magid, L., Shokri, S.Z., Selim, Z. (1998). A unit commitment by Tabu search. IEE Proceedings - Generation, Transmission, and Distribution, 145(1), 56-64.

Misevičius, A., Rubliauskas, D. (2009). Testing of hybrid genetic algorithms for structured quadratic assignment problems. Informatica, 20(2), 255-272.

Mohan, M.R., Kuppusamy, K., Khan, M.A. (1992). Optimal short-term hydro-thermal scheduling using decomposition approach and linear programming method. International Journal of Electrical Power \& Energy Systems, 14(1), 39-44.

Ngundam, J.M., Kenfack, F., Tatietse, T.T. (2002). Optimal scheduling of large-scale hydrothermal power systems using the Lagrangian relaxation technique. International Journal of Electrical Power \& Energy Systems, 22(1), 237-245.

Padhy, N.P. (2000). Unit commitment using hybrid models: a comparative study for dynamic programming, expert systems, fuzzy system and genetic algorithms. International Journal of Electrical Power \& Energy Systems, 23(1), 827-836.

Press, W.H., Teuko, S.A. (2002). Numerical Recipes in $\mathrm{C}++$ : The Art of Scientific Computing. Cambridge.

Price, K.V. (1997). Differential evolution vs. the functions of the 2nd ICEO. In: Proceedings IEEE Evolutionary Computation Conference, pp. 153-157.

Sheble, G.B. (1990). Solution of the unit commitment problem by the method of unit periods. IEEE Transactions on Power Systems, 5(1), 257-260.

Sisworahardjo, N.S., El-Kaib, A.A. (2002). Unit commitment using ant colony search algorithm. In: Proceedings 2002 Large Engineering Systems Conference Power Engineering, pp. 2-6.

Snyder, Jr. W.L., Powell Jr., H.D., Rayburn, J.C. (1987). Dynamic programming approach to unit commitment. IEEE Transactions on Power Systems, 2, 339-350. 
Storn, R. (1999). System design by constraint adaptation and differential evolution. IEEE Transactions on Computation Conference, 3(3), 22-34.

Storn, R., Price, K. (1996). Minimizing the real functions of the ICEC' 96 contest by differential evolution. In: Proceedings IEEE Evolutionary Computation Conference, pp. 842-844.

Ting, T.O., Rao, M.V.C., Loo, C.K., Ngu, S.S. (2003). Solving unit commitment problem using hybrid particle swarm optimization. Journal of Heuristics, 9, 507-520.

Wood, A.J., Wollenberg, B.F. (1996). Power Generation, Operation and Control. Wiley, New York.

Yang, H.T., Yang, P.C., Huang, C.L. (1996). Evolutionary programming based economic dispatch for units with non-smooth fuel cost functions. IEEE Transactions on Power Systems, 1(1), 112-117.

Zhuang, F.L., Galiana, F.D. (1990). Unit commitment by simulated annealing. IEEE Transactions on Power Systems, 5(1), 311-317.

C.-S. Chang is an associate professor of information management at Nan-Kai Institute of Technology. He received his Ph.D. in electrical engineering from National Taiwan University in 1999. From 1988 to 2002 he was with the Chunghwa Telecom. Co., Ltd. for Dept. of Information Management. His research interests include the applications of artificial intelligence, soft computing and value-at-risk in power system.

\section{Pagerinta diferencialinès evoliucijos schema didelio matavimo bloku perjungimo problemoms spręsti}

\section{Chen-Sung CHANG}

Šiame straipsnyje pateikiamas pagerintas diferencialinès evoliucijos (PDE) metodas didelio matavimo bloku perjungimo problemoms spręsti. Nagrinėjamoje schemoje tikslo funkcija yra skirta sudaryti generavimo tvarkaraštị, minimizuojantị bendrus aptarnavimo kaštus per duotą laiką esant duotai ribojimu aibei. Pritaikant patobulintus akseleracijos ir migracijos procesus, PDE metodas riboja populiacijos dydị, naudojamą paieškos procedūroje, ir todèl idealiai tinka spręsti didelio matavimo kombinatorinèms problemoms. Sukurto metodo efektyvumas patikrintas imitavimo būdu pasinaudojant praktinès Tai energetinès sistemos ir kitụ energetinių sistemų, žinomų literatūroje, duomenimis. Bendru atveju, gauti rezultatai leidžia tvirtinti, jog PDE schema yra pranašesnè už žinomus deterministinio ir stochastinio optimizavimo metodus gauto sprendinio kokybès ir skaičiavimo sąnaudų požiūriu. Dar daugiau, taikant šią schemą kaštų sumažejimas, pasiektas dèka PDE schemos, didèja didèjant generavimo bloku, ijungtụ ị energetinę sistemą, skaičiui. Tokiu būdu, pasūlyta schema pateikia ypač efektyvų būdą didelio matavimo blokų perjungimo uždaviniams spręsti. 